\title{
Luxo e sofisticação nas vitrines da Borges: gentrificação comercial e turismo no espaço urbano de Gramado (RS)
}

Lujo y sofisticación en las vitrinas de Borges: gentrificación comercial y turismo en el espacio urbano de Gramado (RS)

Luxury and sophistication in the showcase of Borges: commercial gentrification and tourism in the urban space of Gramado (RS)

Daniel Luciano Gevehr

Faculdades Integradas de Taquara (FACCAT), Brasil

DOI: https://doi.org/10.18472/cvt.19n3.2019.1498

danielgevehr@hotmail.com

Redalyc: http://www.redalyc.org/articulo.oa? $\mathrm{id}=115461709005$

Franciele Berti

Faculdades Integradas de Taquara (FACCAT), Brasil

francieleberti@hotmail.com

Recepción: 28 Septiembre 2017

Aprobación: 05 Junio 2019

\section{Resumo:}

Investiga-se a atividade turística enquanto fator de transformação da paisagem da Avenida Borges de Medeiros, principal avenida central do espaço urbano de Gramado (RS). A análise privilegia o processo de gentrificação (GANT, 2015 ; GOTHAM, 2005; LEY, 1980, 1986, 2003 ; SMITH, 1979, 1982, 1996, 2002) que está ocorrendo na área central do município. O procedimento metodológico compreende: (i) revisão bibliográfica; (ii) pesquisa documental, (iii) visita de campo, adotando-se a observação sistemática e (iv) entrevistas semiestruturadas. Perpassando por determinadas décadas, o recorte temporal da análise compreende os séculos XX e XXI. Os resultados evidenciam que as residências unifamiliares, fábricas e vendas frequentadas pela classe trabalhadora, converteram-se em prédios comerciais, que abrigam, em sua maioria, butiques, restaurantes e equipamentos turísticos, demonstrando um significativo processo de elitização do comércio local.

Palavras-CHaVE: Segregação, Espaço urbano, Gramado.

\section{Abstract:}

The tourist activity is investigated as a factor of transformation of the landscape of Avenida Borges de Medeiros, main central avenue of the urban space of Gramado (RS). The analysis favors the process of gentrification (GANT, 2015; GOTHAM, 2005; LEY , 1980, 1986, 2003, SMITH, 1979, 1982, 1996, 2002,) that is occurring in the central area of the municipality. The methodological procedure comprises: (i) bibliographic review; (ii) documentary research, (iii) field visit, adopting systematic observation and (iv) semi-structured interviews. Passing through certain decades, the temporal cut of the analysis comprises XX and XXI centuries. The results show that single-family residences, factories and sales frequented by the working class have become commercial buildings, which mostly house boutiques, restaurants and tourist facilities, demonstrating a significant process of elitizing local commerce.

KEYWORDS: Commercial Gentrification, Urban space, Gramado.

\section{Resumen:}

Se investiga la actividad turística como factor de transformación del paisaje de la Avenida Borges de Medeiros, principal avenida central del espacio urbano de Gramado (RS). El análisis privilegia el proceso de gentrificación (GANT, 2015; , , GOTHAM, 2005; LEY, 1980, 1986, 2003 ; SMITH, 1979, 1982, 1996, 2002) que está ocurriendo en el área central del municipio. El procedimiento metodológico comprende: (i) revisión bibliográfica; (ii) investigación documental, (iii) visita de campo, adoptando la observación sistemática y (iv) entrevistas semiestructuradas. Pasando por determinadas décadas, el recorte temporal del análisis comprende el siglo XX y XXI. Los resultados evidencian que las residencias unifamiliares, fábricas y ventas frecuentadas por la clase trabajadora, se convirtieron en edificios comerciales, que albergan, en su mayoría, boutiques, restaurantes y equipamientos turísticos, demostrando un significativo proceso de elitización del comercio local. Palabras clave: Gentrificación comercial; Espacio urbano; Gramado. INTRODUÇÃO 


\section{INTRODUÇÃO}

Enquanto atividade econômica, o turismo consome, transforma [e também produz] espaços para que possa acontecer (LUCHIARI, 1998). Essa condição, resulta em diversas transformações no espaço, manifestadas de acordo com a intensidade da atividade turística, entre muitas outras possibilidades e interesse. É possível afirmar que o turismo é um produto que, por conseguinte, acompanha as necessidades do mercado (MESQUITA, 2006), incidindo no consumo de "mercadorias turísticas” que compõe a localidade, sejam elas a paisagem cultural, shows, restaurantes, hotéis, entre outros (AGUIAR 2005).

Sob a perspectiva das transformações citadinas, a análise parte do conceito de gentrificação, processo observado na área central de Gramado (RS). Partimos do entendimento que, gentrificação é um fenômeno segregador, em que ocorre a supressão das classes trabalhadoras de uma determinada área, sendo gradualmente substituídas pela classe média e alta (SMITH, 1979).

Durante o desenvolvimento dos estudos sobre o fenômeno social da gentrificação, a teoria [da gentrificação] se ramificou, abrangendo uma visão global do fenômeno que extrapola as alterações na composição da habitação, assim, outros conceitos foram inseridos na literatura, tais como gentrificação turística (GOTHAM, 2005) e gentrificação comercial (GANT, 2015). Esses dois conceitos, é que permitirão, melhor compreender a dinâmica do espaço urbano de Gramado.

Este estudo tem como objetivo analisar como a atividade turística tem atuado, enquanto fator de transformação, no espaço urbano central de Gramado (RS), localidade considerada pelo Ministério do Turismo (2015) como destino turístico consolidado. Mais especificamente, a análise enfoca a Avenida Borges de Medeiros, uma das primeiras vias abertas pelos colonizadores que chegaram ao município e, atualmente publicizada pela municipalidade como um "shopping a céu aberto."

O procedimento metodológico compreendeu, inicialmente, coleta de informações por meio de revisão bibliográfica referente a gentrificação (LEY, 1980, 1986, 2003; SMITH, 1979, 1982, 1996, 2002 ); gentrificação turística (GOTHAM, 2005) e gentrificação comercial (GANT, 2015); em seguida, foram selecionados 20 lotes [como amostragem], visando mapear seus os diversos usos, percorrer [por meio de pesquisa documental] os processos de transformações sofridos pelos mesmos.

A fonte documental envolveu registros fotográficos, coletados pelos autores, no Arquivo Público Municipal João Leopoldo Lied, em 2016, bem como em obras que tratam da história do município [produzidas por memorialistas da cidade]. As imagens disponíveis nas referidas produções são provenientes de acervos familiares dos respectivos autores. No que tange as fotografias, coletadas no arquivo municipal, essas são doações [especialmente de moradores] ou registros realizados pela prefeitura municipal. Procurando melhor estruturar a pesquisa, mostramos, na Imagem 1, os lotes selecionados na Avenida Borges de Medeiros e que serão objeto de investigação da pesquisa. 


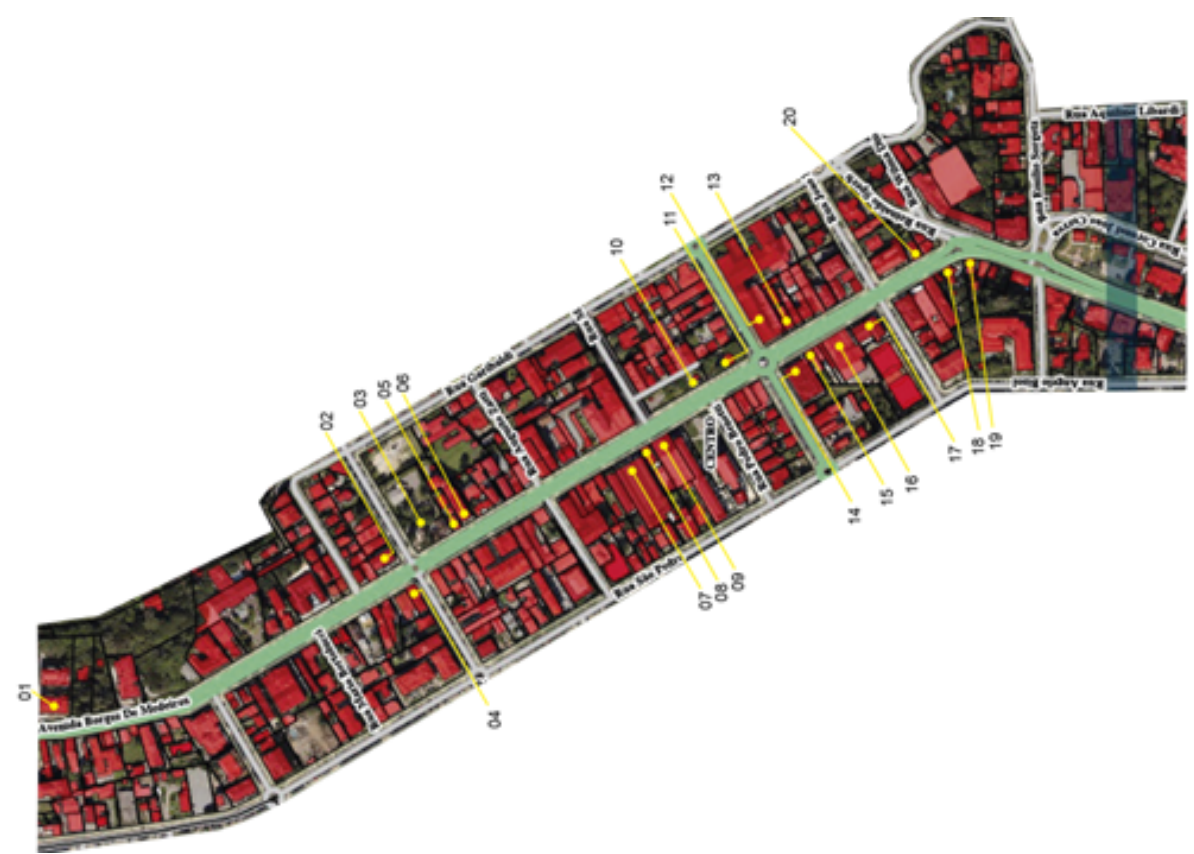

Imagem 1 - Delimitação dos lotes de estudo - Avenida Borges de Medeiros, Gramado (RS)

Fonte: elaborado pelos autores

Para o recorte temporal da análise, buscou-se, preferencialmente, imagens do início do século XX e, para fins de comparação, a fotografia do mesmo ângulo, na segunda metade do mesmo século e, posteriormente, em 2017. Não sendo possível localizar imagens do início do século, utilizou-se a fotografia mais antiga disponível.

Após a análise documental, visando preencher lacunas que se abriram no decorrer do estudo e, optando-se por amostras não probabilísticas intencionais, realizou-se entrevistas semiestruturadas, tendo como universo atores sociais, os quais estavam, direta ou indiretamente, envolvidos na problemática abordada.

Essa metodologia d e pesquisa adotada foi fundamental para a obtenção de informações sobre a dinâmica das transformações do espaço urbano gramadenses, que não se encontram, devidamente registradas em outras pesquisas. Na maioria das vezes, o que se teve acesso, foram informações dadas pelos moradores das imediações da zona central da cidade ou, registros em obras produzidas por memorialistas locais, que sem a utilização de um método científico, acabaram registrando parte das memórias da cidade.

Desta forma, com vistas a confirmar, confrontar ou aprofundar a análise dos dados coletados nas outras fontes, realizou-se visita de campo, adotando-se a observação sistemática. Durante a visita de campo, estabeleceu-se diálogo com moradores do entorno dos lotes. Na oportunidade realizou-se, também, o registro fotográfico dos lotes, atentando-se para o mesmo ângulo da imagem de referência.

\section{A (RE)PRODUÇÃO DO ESPAÇO TURÍSTICO E A GENTRIFICAÇÃO}

A Produção do espaço é um conceito que tem sido frequentemente citado na literatura. Conforme afirma Schmid (2012), o conceito tem passado por consideráveis releituras nos últimos anos. A tese central de Lefebvre (1991) propõe que o espaço está fundamentalmente vinculado à realidade social. Neste mesmo sentido, Furtado (2011) afirma que todas as atividades humanas, apoiadas em estruturas físicas apropriadas, regras, regulamentações e serviços, implicam no uso de solo.

A produção do espaço é encaminhada. de acordo com as atividades diárias e arranjo espacial, resultante dessas atividades, tais como lazer, educação, trabalho e descanso, realizadas pelas pessoas que vivem no local (CAVALCANTI, 2001). Nessa perspectiva, o espaço é produzido conforme se produz a vida cotidiana dos indivíduos, é, assim, a materialização do conteúdo das relações sociais. 
A conexão entre turismo e espaço é explicitamente estreita, tendo em vista que a atividade turística, desenvolve-se como um fenômeno essencialmente espacial. $\mathrm{O}$ fenômeno turístico vem sendo estudado consideravelmente pela geografia, enriquecendo o debate acerca do tema (JIMÉNEZ, NECHAR; VEGA, 2014), sendo o fator espacial do fenômeno turístico o detentor do principal motivo pelos quais essa área do conhecimento têm se debruçado no assunto (AGUIAR, 2005).

Considerando-se essa caracterização de atividade essencialmente espacial, uma vez que consome, transforma e também produz espaços para que possa acontecer (CORIOLANO, 2006; LUCHIARI, 1998; ; VARAJÃO; DINIZ, 2014), o turismo pode ser consideravelmente impactante, exercendo influência para modificar inteiramente determinados locais para que possa se desenvolver (OLIVEIRA ; VITTE, 2004).

Luchiari (1998) e Silva (2012) ampliam a discussão, afirmando que a gama de transformações sobre um núcleo pode ser maior ainda quando não existe vocação natural para o turismo, sendo artificial, "fabricada" ou imposta, tendo em vista que é preciso sobrevir uma profunda reestruturação espacial a fim de reproduzir um novo arranjo do espaço. A atividade turística tem impacto expressivo na formação urbana e, nesse caso, a morfologia citadina, tende a seguir um padrão, em que o núcleo tradicionalmente, encontra-se dominado pelo varejo e instalações de entretenimento em detrimento de escritórios e, no seu entorno imediato, encontram-se os hotéis de luxo e edifícios residenciais de alto nível (FAINSTEIN; GLADSTONE, 1999). Incontestavelmente, é sobre os núcleos turísticos que o turismo vai impor a maior gama de transformações socioespaciais. Nos territórios receptores de fluxos de turistas, multiplicam-se infraestruturas relativas à hospedagem, que podem ser, desde pousadas rústicas até hotéis de padrão internacional ou, ainda, loteamentos e condomínios de segunda residência (CRUZ, 2003).

O termo gentrificação é atribuído, originalmente à socióloga Ruth Glass, que cunhou o vocábulo na década de 1960, definindo o fenômeno de retorno da classe média ao centro de Londres, que expulsou moradores da classe operária que habitavam o local (SMITH, 1996). Na década de 1970 surgiram os projetos de renovação urbana, que visavam conter a expansão periférica, migrando o crescimento da periferia para o centro, estimulando um processo retorno ao centro (FURTADO, 2011). As melhorias resultaram em intensificação do uso do solo e em aumento do preço na área central da cidade. No entanto, as renovações resultaram em expulsão de seus ocupantes de baixa renda.

Para Siqueira (2014), os casos brasileiros de gentrificação, como Gramado, dificilmente poderão ser explicados por meio da teoria clássica da gentrificação. A autora postula que, diferentemente das experiências norte-americanas e europeias, a gentrificação encontrada no Brasil — tal como em outros países como China, Índia e mesmo contemporaneamente nos países berços da teoria - não está relacionada ao processo de reversão da suburbanização. Neste sentido, o processo não percorre as fases iniciais, estando diretamente vinculado à expansão do urbanismo neoliberal, em que ocorre a intensificação da prática indiscriminada do planejamento urbano, como ferramenta do capital, uma vez que as políticas urbanas sofrem mudanças de acordo com a necessidade de pequenos grupos (ARANTES, 2015).

Nessa conjuntura, a teoria da gentrificação se ramificou, abrangendo uma visão global do fenômeno, assim, outros conceitos foram inseridos na literatura, tais como gentrificação turística (GOTHAM, 2005) e gentrificação comercial (GANT, 2015). Essa última, segundo Gant (2015), resulta das melhorias na infraestrutura e serviços para atender a demanda turística - de classe média . A gentrificação que o turismo mais tem causado é a chamada gentrificação comercial, dado que nas cidades turísticas tende a predominar lojas e locais de entretenimento e raras são as extensões residenciais da classe operária em espaço central (GANT, 2015).

Acredita-se que as áreas urbanas podem ser reutilizadas, não somente, para habitação, mas para a instalação de outros usos, tais como alterações nos espaços visando aumentar a atividade turística. O deslocamento suscitado pela gentrificação do turismo tem sido observado na literatura, nesse contexto, o elemento impulsor da gentrificação não se limita a dinâmicas essencialmente residenciais (CERQUEIRA, 2014). 
Tem-se Gramado - compreendido como objeto da pesquisa - com uma população de 32.273 habitantes (IBGE, 2010) em uma área de $237,827 \mathrm{~km}^{2}$ (IBGE, 2015). Atualmente configura-se como imagem de destino consolidado, tendo seu potencial turístico cada vez mais explorado (MINISTÉRIO DO TURISMO, 2015). O município está localizado na denominada "Região das Hortênsias". Tal regionalização abrange também os municípios de Canela, São Francisco de Paula e Nova Petrópolis.

A Avenida Borges de Medeiros - recorte espacial deste estudo - é uma via estrutural[1] de Gramado, considerada cartão postal do município que abriga ao longo dos seus 7,784 $\mathrm{Km}$ de extensão alguns dos principais equipamentos turísticos da região, como Palácio dos Festivais, a Praça Major Nicoletti e Igreja São Pedro.

Valendo-se da pesquisa documental, a partir da análise de imagens e registros em livros que narram a história do município, verifica-se que outrora a mencionada Avenida era caracterizada, fundamentalmente, como residencial, apresentando, também, algumas vendas, fábricas e pensões, essas últimas destinadas aos veranistas que já visitavam o local. Conforme destaca Casagrande (2006), no início de sua formação [início do século XX], ainda que já apresentasse direcionamento para o turismo, o centro urbano de Gramado não se diferenciava dos outros vilarejos do sul do Brasil.

Corrobora com tal afirmação, a memorialista Daros (2008) - nascida e domiciliada na Avenida Borges de Medeiros - ao afirmar que o logradouro era uma rua tradicionalmente residencial, apresentando algumas casas de comércio que, no entanto, foram se afastando no decorrer dos anos. Daros (2008) ainda faz menção a enobrecimento da área central: "[...] Com o tempo, o comércio foi afastando as antigas famílias que foram comercializando os espaços nobres desta avenida [...]" (DAROS, 2008, p. 399).

Sabe-se que, no final da década de 1910, iniciam-se as instalações de meios de hospedagens em Gramado, primeiramente tendo como público "viajantes de tecidos e carreteiros" (KOPPE DRECKSLER, 1993). Entretanto, posteriormente, Gramado apresenta-se como destino turístico das famílias abastadas de localidades próximas, como Porto Alegre [capital do estado do Rio Grande do Sul], que vinham ao município à procura de descanso e lazer. Conforme Koppe e Drecksler (1993, p. 104) "Os veranistas eram árabes, judeus, alemães, italianos e portugueses. Muito educados, elegantes [...], adoravam nossas belezas naturais, donos de finas lojas e atacados de Porto Alegre.”.

O final da década de 1930 parece estar, particularmente, associado ao fortalecimento da aproximação da alta sociedade a Gramado. Em 1937 ocorre a inauguração da "Vila Planalto Gramado", um loteamento dos herdeiros da baronesa Joaquina Rita Bier, direcionado, especialmente, a veranistas com interesse em imóveis para fins de segunda residência (KOPPE ; DRECKSLER, 1993). Após a referida inauguração, gradativamente Gramado, e particularmente a área central do município, passam por transformações. Conforme observa Casagrande (2006), neste período é possível observar os primeiros sinais de consideráveis transformações da localidade:

[...] Gramado, assim como Canela, passam a receber um número de pessoas cada vez maior e mais exigente e, aos poucos, o cotidiano dessas duas comunidades passa por metamorfoses. As famílias mais abastadas de Porto Alegre, Novo Hamburgo e São Leopoldo começaram a construir casas nos arredores do centro da Vila (CASAGRANDE, 2006, p. 34, grifo nosso).

Já na década de 1940, Gramado dispõe de 4 equipamentos de hospedagem, todos localizados na Avenida Borges de Medeiros (BEHREND, 1999). Em 1987 - período de expansão do turismo na cidade - registra 29 hotéis e pousadas (GRAMADO, 1987), o que evidencia o paulatino desenvolvimento turístico que ocorria no local. A década de 2000, por sua vez, apresenta uma explosão no número de meios de hospedagem. De acordo com a Prefeitura Municipal de Gramado, em 2016, entre hotéis e pousadas, há 176 estabelecimentos cadastrados, cuja oferta total ultrapassa 13 mil leitos. Em menos de três décadas o segmento apresentou um crescimento de $500 \%$.

O panorama descrito por Gant (2015) esboça-se na área analisada, observando-se algumas edificações sendo reconvertidas para novos usos. Neste prisma, destacamos um edifício que na década de 1940, de 
acordo com o relato da atual proprietária do prédio [neta do primeiro proprietário], abrigava uma tradicional cafeteira, frequentada habitualmente pela classe trabalhadora. A parte superior da construção de dois pavimentos acomodava a residência da família administradora do estabelecimento comercial, enquanto o térreo comportava a cafeteria, ponto de encontro de colonos e carreteiros da região.

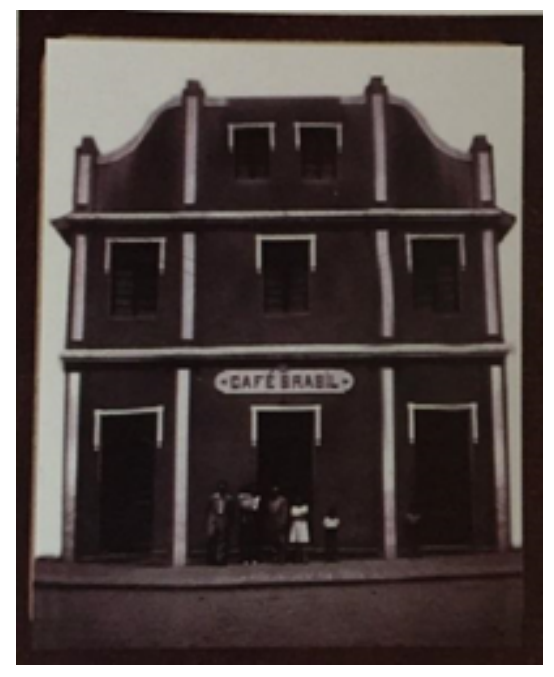

Imagem 2 - Cafeteria e ponto de encontro de colonos e carreteiros (Década de 1940) Fonte: Drecksler (2012)

A edificação se destaca, tendo em vista sua construção em alvenaria e elaborados contornos externos, distinguindo-se das demais [em que há predomínio de madeira e traços simples]. O estabelecimento possuía duas janelas centrais no sótão, no segundo pavimento percebem-se mais três janelas, sendo uma central e duas laterais e, ainda, o térreo, que abrigava a cafeteria.

Infere-se que por mais três décadas a edificação permaneceu com função mista, ou seja, sendo utilizada para fins habitacionais e comerciais. Desde a década de 1970, a utilização do edifício é exclusivamente comercial, abrigando, desde então, restaurante. Em 2011 o imóvel passa a abrigar uma butique [tipo de estabelecimento comercial cada vez mais presente na Avenida central da cidade] voltada principalmente para os turistas.

Atualmente, preservando parcialmente a mesma estrutura, há uma franquia de uma grife de bolsas, calçados e acessórios (Imagem 3). A loja, inaugurada em $2011 \mathrm{com}$ a presença de atrizes e modelos nacionais, tem 200 lojas distribuídas em 16 países, sendo a filial de Gramado a segunda da franquia, enquadrada como concept store. Essa proposta de comércio concentra-se na "promoção de um universo temático" - tal como luxo e design -, para tanto, a estética do espaço é adequada objetivando proporcionar um ambiente que visa oferecer uma experiência com o espaço de venda e não somente de compra (CERQUEIRA, 2014, p. 426). Vale mencionar, ainda, que a primeira loja da marca com esse conceito está instalada na Rua Oscar Freire, situada em um dos bairros nobres de São Paulo. 


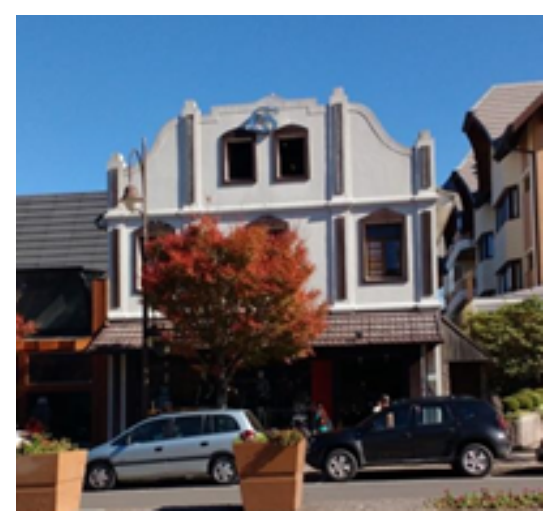

Imagem 3 - Butique em Gramado (2017)

Fonte: acervo dos autores (2017)

O empreendimento de $420 \mathrm{~m}^{2}$ recebeu iluminação interna sofisticada e cores externas neutras (branco e marrom), que harmonizam com a cenografia estabelecida na Avenida. O sótão e o pavimento superior comportam showroom, outlet e, no térreo, a loja.

Embora tenha sido preservada a edificação original, algumas alterações podem ser percebidas na fachada: as três portas do térreo foram transformadas em uma longa vitrine, a porta principal foi acomodada à direita e uma estreita marquise foi posta logo acima da vitrine. De acordo com o website da grife, a empresa lança até onze coleções anuais, não permitindo a venda em massa de seus produtos, tal panorama nos leva a compreender que as peças destinam-se a um seleto público-alvo de alto poder aquisitivo.

$\mathrm{Na}$ Imagem 3, é possível perceber, também, o processo de embelezamento da vegetação dos arredores. A tendência de "ornamentação da vegetação local” de Gramado é destacada por Dorneles (2001, p. 50), especialmente no âmbito de rearborização urbana. De acordo com o autor, a rearborização se deu em parceria entre a Prefeitura de Gramado e uma instituição universitária. Para essa nova arborização, selecionaram-se árvores caducifólias - objetivando aumentar a insolação da cidade nos meses de inverno -, além disso, o processo de triagem levou em consideração a atratividade paisagística das espécies (DORNELES, 2001).

Segundo o mesmo estudo, a vegetação selecionada visa produzir um efeito de padronização das vias centrais do município, criando um ambiente que remete a associação de uma "paisagem europeia", proporcionando valorização por parte dos visitantes. A presença de espécies como os ciprestes, as árvores originárias de clima temperado e o colorido das flores de época [begônias, gerânios e amor-perfeito] procuram dar um ar de sofisticação para os visitantes.

A edificação apresentada anteriormente era utilizada como residência e comércio, e esse quadro é observado também em outros lotes, sendo percebida como uma prática comum no início do século XX. A instalação dos estabelecimentos mais antigos parece associada à proximidade da residência dos comerciantes, ou à disponibilidade de espaços desocupados.

Já a implantação das atuais atividades comerciais nos parece premeditada. Conforme menciona Cerqueira (2014, p. 428) "A concentração de atividades destinadas a uma clientela qualificada estimula um tipo de negócio que se embasa sobre a especificidade do público que a zona atrai, composto essencialmente por indivíduos com um elevado poder aquisitivo".

Outro exemplo revelador das transformações do espaço central da cidade se verifica na evolução sofrida no Lote 16, que presenciou uma substancial mudança na sua finalidade. Em 1934, a casa grande, rudimentar, construída em longas tábuas verticais sem pintura e telhado de duas águas, fortemente inclinado, abrigava um moinho (Imagem 4). 


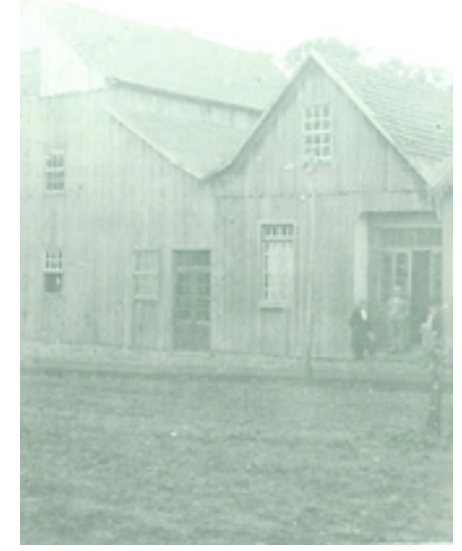

Imagem 4 - Moinho São Pedro (Década de 1930)

Fonte: Koppe e Drecksler (1993)

Embora careça de registros fotográficos do período, sabe-se [por meio da memória da comunidade] que na década de 1940 o empreendimento se desenvolveu, tornando a construção obsoleta, sendo substituída - como informa Koppe e Drecksler (1993) - por uma edificação de alvenaria. Em 1964, devido, principalmente, ao desestímulo do governo em relação ao subsídio do trigo, o moinho encerrou suas atividades.

De acordo com relato de moradores - realizado de forma direta pelos pesquisadores, em saída de campo das proximidades do lote, na década de 1970 a estrutura abrigava um supermercado pertencente a uma rede nacional, cujo público era formado, essencialmente, por moradores e turistas hospedados no entorno. Em 2008, após a rede de supermercado ser vendida, outra empresa do mesmo ramo assume o estabelecimento, permanecendo por mais seis anos na Avenida Borges de Medeiros.

$\mathrm{Na}$ imagem 5 observa-se a fachada frontal do estabelecimento, como ela se apresentava até 2011. A edificação, de gabarito baixo e telhados de duas águas vigorosamente inclinadas, parece ser fracionada em duas partes, sendo a primeira levemente mais alta. Embora a arquitetura já estivesse em conformidade com as demais estabelecidas na Avenida, chama atenção a cor do edifício, que em nada se aproxima das cores sóbrias normalmente eleitas para as atuais edificações da Borges de Medeiros: a coloração das paredes externas assemelha-se com azul turquesa com detalhes em madeira e o telhado verde-musgo.

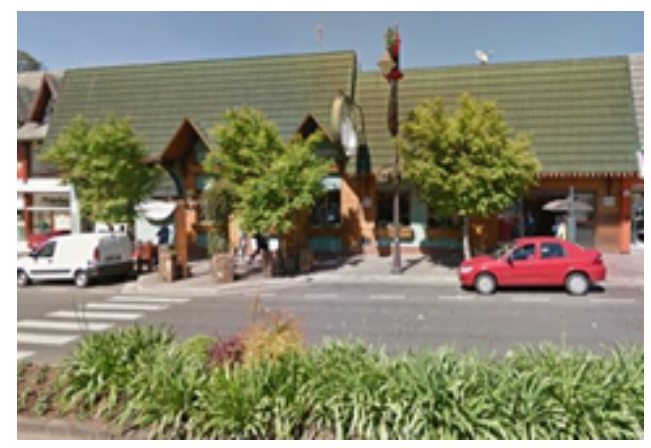

Imagem 5 - Supermercado (2011)

Fonte: Google Street View (2011)

Em 2014 o empreendimento encerra suas atividades e, no que se refere a justificativa para o fechamento, de acordo com o site de notícias local do jornalista Miron Neto: "[...] O motivo do encerramento das operações foi o aumento que era pedido pelo proprietário do imóvel para a renovação do contrato de 
aluguel [...]." (MIRON NETO, 2014). Há que se ressaltar que o deslocamento suscitado pela valorização de determinadas áreas tem sido amplamente discutido na literatura que discorre sobre a gentrificação.

Ainda que determinadas afirmações quanto ao deslocamento das classes menos abastadas economicamente sejam rebatidas em alguns estudos - devido à dificuldade de desenvolver metodologias que sejam capazes de rastrear os moradores que são deslocados - existe um certo consenso entre os pesquisadores, no que se refere ao efeito de expulsão, que a gentrificação promove (ATKINSON, 2002).

Retomando a discussão relativa à trajetória do lote, a significativa transfiguração de uso ocorre no ano subsequente ao fechamento do supermercado, quando instala-se no local um parque temático de chocolate. De acordo com o website do empreendimento, o parque oferece um tour por mais de duzentas esculturas de chocolates, expostas em um espaço de $3 \mathrm{mil} \mathrm{m}^{2}$.

Dentre os monumentos - esculpidos em chocolate maciço - pode-se citar bolsas, animais, objetos de decoração, o Cristo Redentor, a Estátua da Liberdade, a Casa Branca, além da Torre Eiffel, que ostenta 4,22 $\mathrm{m}$ de altura e pesa mais de $800 \mathrm{Kg}$. O complexo dispóe, ainda, de um espaço para café; uma mini fábrica, em que o visitante tem a experiência de ser "chef por um dia", criando a sua própria versão do doce; área de degustação e, por fim, uma loja que comercializa chocolate [ambos voltados especialmente para o turista]. A Imagem 6 registra o mesmo prédio, após as modificações - realizadas entre 2014 e 2015. A fachada frontal foi inteiramente remodelada, recebendo duas torres laterais em madeira, o telhado novo entre as torres, com forte inclinação frontal e detalhes vazados.

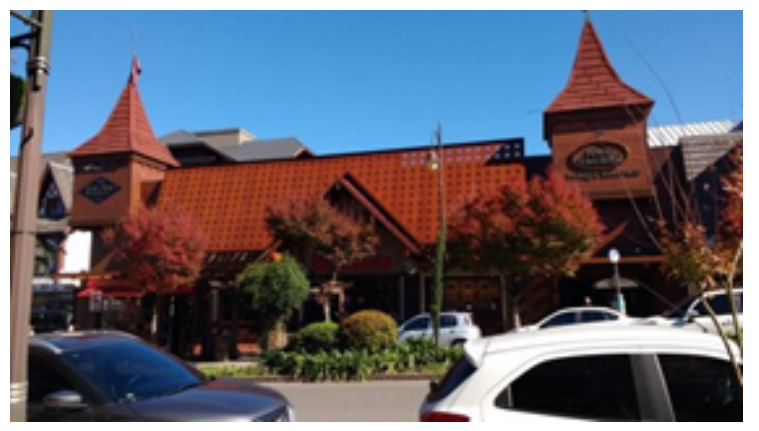

Imagem 6 - empreendimento turístico do ramo do chocolate Fonte: acervo dos autores (2017)

Conforme é possível observar na Imagem 6, na edificação é explorada de forma acentuada a coloração marrom, possivelmente como referência ao chocolate. No cenário construído em Gramado pelo comércio de chocolate, conforme proposto por Vargas e Gastal (2015), observa-se uma bifurcação nas tendências visuais: de um lado, empresas que estimulam o "imaginário do caseiro" no seu produto e locais de venda, em que são exploradas, por meio da decoração, as cores sóbrias e apelo "tradicional”; do outro lado empresas que utilizam a tematização, em que as vitrines e fachadas tem apelo lúdico e se destacam no contexto urbano no qual estão inseridos. Neste sentido, o chocolate também extrapola a função alimentícia, sendo inspiração para parques temáticos locais como esse descrito.

Torna-se pertinente destacar que a história do doce em Gramado tem origem em 1976, quando Jayme Prawer implantou no município a primeira fábrica de chocolate caseiro, algo inédito no Brasil. Atualmente estão registradas 21 fábricas de chocolates em Gramado, sendo o comércio do produto destaque na composição da paisagem da Avenida Borges de Medeiros, que exibe mais de 10 lojas do gênero nas proximidades do Palácio dos Festivais (GRAMADO, 2016). De acordo com Vargas e Gastal (2015) paralelo a outras atividades, o chocolate foi relevante para o desenvolvimento do município, atingindo, contemporaneamente, dimensões que o tornaram um "ícone gramadense". Segundo as autoras, o chocolate ocupa lugar de destaque nas intenções de compra dos turistas que visitam Gramado, tendo em vista sua forte associação à "marca Gramado", fazendo com que os visitantes se refiram ao chocolate como "o chocolate de Gramado”. 
$\mathrm{Na}$ contramão do enfraquecimento de atividades de caráter popular e tradicionais, vinculadas à cultural local como o artesanato[2], observa-se a multiplicação de atividades destinadas aos visitantes. A Avenida está voltada para o segmento comercial, concentrando estabelecimentos fundamentalmente direcionados ao turista, enquanto os serviços destinados a moradores encontram-se nas ruas paralelas à Avenida (RIGATTI, 2002). Por meio da análise das imagens dos lotes, nota-se a evolução dos estabelecimentos comerciais e a gradativa substituição de residências pelo comércio, especialmente aqueles destinados aos grupos mais elitizados e com poder de aquisição dos lotes, cujo valor financeiro aumenta progressivamente.

Aproximando a discussão sobre a transformação da Avenida Borges de Medeiros com a teoria proposta por Gant (2015), verifica-se que a gentrificação que tem se desenvolvido na área central de Gramado apresentase com uma tipologia comercial, impulsionada pela crescente desindustrialização e o aumento da atividade turística.

A avenida moldou-se às necessidades da demanda do turismo, suscitando a elitização do comércio local, transformando-se no que Sánchez (2010, p. 489) chama de "playgrounds da burguesia” onde coexistem shoppings centers, butiques, cafés, restaurantes de grife, hotéis, entre outros. Assim, o centro da cidade passa a pertencer mais aos visitantes mais abastados do que aos moradores, resultando na exclusão dos residentes da classe trabalhadora (FAINSTEIN; GLADSTONE, 1999).

A década de 2000 está particularmente associada às mudanças significativas da área, tendo em vista que representa um período de intensas mudanças. Tais alterações foram significativas para o reordenamento da área central da cidade, que passa a se organizar cada vez mais para o turismo. Tem-se como uma dessas mudanças a requalificação da Avenida que, embora não estivesse em processo de degradação — a via estava completando cinquenta anos quando o projeto de revitalização foi apresentado à comunidade, recebeu uma remodelação de grande proporção. $\mathrm{O}$ investimento de aproximadamente cinco milhões e meio de reais, envolveu a eliminação das redes de fiação aérea; instalação de novos postes, ornados por floreiras suspensas [tornando-os, também, elementos decorativos]; padronização das calçadas; inserção de rótulas luminosas, nivelamento e recapeamento da Avenida; implantação de canteiros com vegetação e iluminação cenográfica em diversos trechos.

Como ensinam Smith (2006) e Arantes (2015), a manifestação da municipalidade [nesse caso, a gramadense] está alicerçada na defesa dos benefícios que a requalificação da área trará para os moradores. O poder público vale-se do discurso de igualdade, no qual se embasa, para justificar as intervenções no tecido urbano, como uma melhoria em que todos os cidadãos serão beneficiados. Contradizendo esse discurso, temos a narrativa do memorialista e antigo morador da Avenida, Carlos Gilberto Drecksler, que afirma:

Será que não conseguem compreender que cada cidade, cada local, tem seu povo, a sua alma, o seu charme? Não precisamos nos transformar em uma grande metrópole, com alto prestígio internacional. Queremos que nos deixem ser o que somos! [...] Querem nos fazer crer que é progresso... As genuínas referências perderam-se. [...]. (DRECKSLER, 2012, p. 9).

\section{CONSIDERAÇÕES FINAIS}

Em diferentes épocas o núcleo central do espaço urbano de Gramado era frequentado por grupos mais abastados [financeiramente]. No entanto, evidencia-se que, inicialmente a Avenida Borges de Medeiros era espaço de convívio da comunidade e de turistas, e, ainda que já abrigasse equipamentos turísticos nas décadas passadas, verificavam-se diversas residências.

Atualmente, a maioria das residências, bem como indústrias e comércios locais, foram substituídos por estabelecimentos voltados ao consumidor de alto padrão. A estrutura urbana da área, tem se transformado, para acomodar a crescente demanda do turismo, multiplicando-se os espaços com função de lazer, recreação e alojamento.

A gentrificação, presente no espaço urbano estudado, permite analisar a dinâmica de produção do espaço da cidade e como essa se articula com diferentes elementos. A atividade turística, nesse caso, é uma das maiores 
responsáveis pelas transformações da zona central de Gramado, onde se percebe uma expressiva - e crescente - preocupação com a estética urbana. A reestilização dos edifícios [com novas finalidades], a utilização de cores, a preocupação com o paisagismo e outros elementos, que podem passar despercebidos num olhar menos atento com a paisagem urbana, revelam a elitização e a sofisticação desse espaço.

Poderíamos ainda pensar esse espaço a partir de outra perspectiva, tendo como ponto fundamental a análise sobre a repercussão da gentrificação turística e comercial, e de forma mais particular, o sentimento de luto e a diminuição do senso de pertencimento na comunidade gramadense. Essa questão, que envolve a sensibilidade dos moradores e seu pertencimento ao lugar, é outro aspecto a ser pensado.

\section{REFERÊNCIAS}

ARANTES, G. F. de. Intervenções Urbanas: rumo à cidade neoliberal. Curitiba, Appris, 2015.

ARREORTUA, L. A. S. (2013), Gentrificación en la ciudad latinoamericana. El caso de Buenos Aires y Ciudad de México. GeoGraphos: Revista Digital para Estudiantes de Geografía y Ciencias Sociales, 44, 4: 281-304.

ATKINSON, R. Does Gentrification Help Or Harm Urban Neighbourhoods? :An Assessment of the Evidencebase in the Context of New Urban Agenda. Bristol: ESRC Centre for Neighbourhood Research, 2002.

BRASIL. Ministério do Turismo. Gramado (RS) aposta na expansão do turismo de negócios, 2015. Disponível em: . Acesso em: 05 set. 2017.

BEHREND, C. (1999). Etapas do Turismo. In: Prefeitura Municipal de Gramado. Raízes de Gramado. Gramado: M\&m.

CASAGRANDE, G. R. Um cheiro do vinho: presença italiana em Gramado. 2006.106 f. Diss. Dissertação de Mestrado, PUCRS Faculdade de Filosofia e Ciências Humanas, Porto Alegre, 2006.

CERQUEIRA, E. D. V. A evolução das formas de gentrificação: estratégias comerciais locais e o contexto parisiense. Cadernos Metrópole., v. 16, n. 32, p. 417-436, 2014.

CORIOLANO, L. N. M. T. Turismo: prática social de apropriação e de dominação de territórios. América Latina: cidade, campo e turismo, organizado por Amalia Geraiges de Lemos, Mónica Arroyo y María Silveira, p. 367-378, 2006. Disponível em . Acesso em: 24 jun. 2016.

CRUZ, R; de C. A. da. Introdução à Geografia do Turismo. 2. ed. São Paulo: Roca, 2003.

DAROS, M. Grãos: coletânea histórica. Gramado: Edição da autora, 2008.

DAVIDSON, M.; LEES, L. New-Build Gentrification: Its Histories, Trajectories, and Critical Geographies. Population, space and place, 16:395-411,2009. Disponível em https://goo.gl/GpFYfg. Acesso em 25 set. 2017.

DORNELES, Edson Bertin. Gramado: a produção e o consumo de uma imagem de uma cidade européia no Brasil. 2001. Dissertação de Mestrado, Universidade Federal do Rio Grande do Sul, Porto Alegre, 2001.

DRECKSLER, C. G. Gramado Contrastes. Porto Alegre: Evangraf, 2012.

FAINSTEIN, S. S.; GLADSTONE, D. Evaluating urban tourism. The tourist city, p. 21-34, 1999.

FURTADO, C. R. Gentrificação e (re)organização urbana em Porto Alegre. Porto Alegre: Ufrgs, 2011.

GANT, A. C. Tourism and commercial gentrification. In: RC21 International Conference, 2015, p. 1- 25, 2015.

GRAMADO. Prefeitura Municipal. Raízes de Gramado. Gramado: [s.n], 1999.

GRAMADO. Secretaria Municipal de Educação. Gramado, simplesmente Gramado. Gramado. Gramado, 1987.

GRAMADO, Secretaria Municipal da Fazenda. Fábricas de chocolate cadastradas em Gramado [mensagem pessoal]. Mensagem recebida por: em: 24 out. 2016.

GOTHAM, K. F. Tourism gentrification: The case of new Orleans' vieux carre (French Quarter). Urban studies, v. 42, n. 7, p. 1099-1121, 2005..

IBGE (INSTITUTO BRASILEIRO DE GEOGRAFIA E ESTATÍSTICA). Censo Demográfico 2010. Disponível em: http://cod.ibge.gov.br/NRF . Acesso em: 12 set. 2016. 
Dados gerais do município. 2015. Disponível em: http://cidades.ibge.gov.br/painel/painel.php? codmun=430910. Acesso em: 15 dez 2016.

KOPPE, I. C.; DRECKSLER, C. G. Era uma Vez...! Relatos de Gramado. Edição Comemorativa aos 25 Anos do Orbis Club de Gramado e 10 anos do Jornal de Gramado. Canoas: Escola Profissional La Salle, 1993.

LEY, D. Liberal ideology and the postindustrial city. Annals of the Association of American Geographers, 70, 2: 238-258, 1980.

. Alternative explanations for inner-city gentrification: a Canadian assessment. Annals of the association of american geographers, 76, 4: 521-535, 1986.

. Artists, aestheticisation and the field of gentrification. Urban studies, 40, 12: 2527-2544, 2003.

LUCHIARI, M. T. D. P. Urbanização turística, um novo nexo entre o lugar e o mundo. Org: LIMA, Luiz Cruz. Da diversidade ao campo: a diversidade do saber-fazer turístico. Fortaleza: UECE, 1998.

MAUAD, A. M. . Sob o Signo da Imagem: a produção da fotografia e o controle dos códigos de representação social da classe dominante, no Rio de Janeiro, na primeira metade do século XX. Tese de doutorado, Universidade Federal Fluminense, Niterói, Rio de Janeiro. 1990

MENDES, L. Gentrificação turística em Lisboa: neoliberalismo, financeirização e urbanismo austeritário em tempos de pós-crise capitalista 2008-2009. Cadernos Metrópole, v. 19, n. 39, p. 479-512, 2017.

NETO, M. Supermercado Imec fecha loja da Avenida Borges de Medeiros. 2014. Disponível em: http:// www.mironneto.com/site/noticia_arquivada.php?noticia=726. Acesso em: 16 maio 2017.

MUNDO DE CHOCOLATE (Gramado). O Parque. Disponível em: http://mundodechocolate.rs/ . Acesso em: 25 set. 2017.

OLIVEIRA, M. R. da S.; VITTE, C. de C. O fenômeno turístico e suas implicações na cidade de Ouro Preto. In: ENCONTRO ANPPAS, 2., 2004, Indaiatuba. Anais.. Indaiatuba: Anppas, 2004. p. 1 - 18. Disponível em: http://www.anppas.org.br/encontro_anual/encontro2/GT/GT15/melissa.pdf. Acesso em: 25 jun. 2016

RIGATTI, D. O turista, o morador e o uso do espaço urbano: interaçóes espaciais em Gramado e Canela. Paisagem e Ambiente, n. 16, p. 69-107, 2002.

SÁNCHEZ, F. A reinvenção das cidades. 2. ed. Chapecó: Unochapecó, 2010.555 p.

SILVA, M. da G. L. Cidades turísticas: identidades e cenários de lazer. Aleph, 2004.

SMITH, N. Gentrification and Capital: Theory, Practice and Ideology in Society Hill, Antipode, 11, 3: 24-35, 1979. ."Gentrification and uneven development". Economic geography, 58, 2: 139-155, 1982.

The new urban frontier: Gentrification and the revanchist city. Psychology Press, 1996.

. New globalism, new urbanism: gentrification as global urban strategy. Antipode, 34, 3: 427-450, 2002.

. A gentrificação generalizada: de uma anomalia local à "regeneração" urbana como estratégia urbana global.

De volta à cidade. São Paulo: Annablume, p. 59-87, 2006.

. (2007), Gentrificação, a fronteira e a reestruturação do espaço urbano. Geousp: Espaço e Tempo, 21:15-31.

VARAJÃO, G. F. D. C.; DINIZ, A. M. A. Turismo, produção do espaço e urbanização: evolução do uso e ocupação do solo de Lavras Novas, Ouro Preto-MG. Caderno de Geografia, Belo Horizonte, v. 24, p.73-89, mar. 2014. Disponível em: http://periodicos.pucminas.br/index.php/geografia/article/view/6660 . Acesso em: 23 jun. 2016.

VAN CRIEKINGEN, M.; FLEURY, A.La ville branchée: gentrification et dynamiques commerciales à Bruxelles et à Paris. Belgeo. Revue belge de géographie, n. 1-2, p. 113-134, 2006.

VARGAS, D. P. de; GASTAL, S. Chocolate e Turismo: o percurso histórico em Gramado, RS. Turismo Visão e Ação, v. 17, n. 1, p. 66-102, 2015.

YOSHINAGA, M. (2007), Hierarquia Viária. Disponível em: https://goo.gl/nhPXei. Acesso em: 9 nov. 2016. 


\section{Notas}

[1] Formam a estrutura viária principal da cidade, destinadas a receber a maior carga de tráfego, definindo os principais acessos da cidade e ligações interurbanas (YOSHINAGA, 2007).

[2] Prática típica em Gramado desde a primeira década do século XX. A presença significativa da cultura do artesanato na cidade originou em 1972 a Feira Nacional do Artesanato (FEARTE), considerado um dos eventos mais prestigiados do município (GRAMADO, 1989). As edições da Feira ocorreram durante dezesseis anos. Em 2015 houve a tentativa de retorno do evento ao calendário de Gramado, no entanto, o evento foi inviabilizado devido à dificuldade para captação de patrocínio.

\section{BY}

